\title{
An Observation of the Clinical and Laboratory Profile in Patients with Sepsis and Severe Sepsis
}

\author{
Al-Aziz $\mathrm{MZ}^{1^{*}}$, Ali $\mathrm{M}^{2}$, Ashrafozzaman $\mathrm{SM}^{3}$, Haque $\mathrm{MJ}^{4}$, Islam $\mathrm{MS}^{5}$, Hasam $\mathrm{T}^{6}$, Gani $\mathrm{ABMS}^{7}$, Amin $\mathrm{MR}^{8}$, Ahasan
} HAMN $^{9}$

\author{
${ }^{1}$ Dr. Mohammad Zakaria Al- Aziz, Assistant Professor, Department of Medicine, Sheikh Hasina Medical College, Tangail, \\ Bangladesh \\ ${ }^{2}$ Dr. Mohammd Ali, HMO, Dhaka Medical College, Dhaka, Bangladesh \\ ${ }^{3}$ Dr. Shaha Md. Ashrafozzaman, Assistant Professor, Department of Medicine, Mymensingh Medical College Hospital, Mymensngh, \\ Bangladesh \\ ${ }^{4}$ Dr. Md. Jahirul Haque, Associate Professor, Department of Medicine, Shahid Sayed Nazrul Islam Medical College, Kishoreganj, \\ Bangldesh. \\ ${ }^{5}$ Dr. Md. Shamiul Islam, Assistant Professor, Department of Cardiology, Sheikh Hasina Medical College, Tangail, Bangladesh \\ ${ }^{6}$ Dr. Towfiq Hasan, Assistant Professor, Department of Respiratory Medicine, Sheikh Hasina Medical College, Tangail, Bangladesh \\ ${ }^{7}$ Dr. ABM Shakil Gani, Assistant Professor, Department of Hepatology, Sheikh Hasina Medical College, Tangail, Bangladesh \\ ${ }^{8}$ Dr. Md. Robed Amin, Associate Professor, Department of Medicine, Dhaka Medical College, Dhaka, Bangladesh \\ ${ }^{9}$ Dr. H. A. M. Nazmul Ahasan, Professor, Department of Medicine, Popular Medical College, Dhaka Bangldesh
}

DOI: $\underline{10.36347 / \text { sjams.2020.v08i12.035 }}$

| Received: 03.12.2020 | Accepted: 16.12.2020 | Published: 29.12.2020

*Corresponding author: Al-Aziz MZ

\section{Abstract}

Original Research Article

Introduction: Sepsis is one of the oldest and most elusive syndromes in Medicine. The clinical manifestations of sepsis are highly variable, depending on the initial site of infection, the causative organism, the pattern of acute organ dysfunction, the underlying health status of the patient, and the interval before initiation of treatment. Aim of this study: To observe the clinical and laboratory profile of patients with sepsis \& severe sepsis as well as hospital mortality at the end of the $1^{\text {st }}$ week. Method: It was hospital based cross sectional, observational study and was carried out in the Department of Medicine, Dhaka Medical College Hospital (DMCH) during the period of January 2015 to December 2015.Patients admitted in the intensive care unit (ICU) of DMCH, who fulfilled the criteria of sepsis or severe sepsis and aged more than 14 Years, among them 100 patients were enrolled in the study. Data from each patient was collected in structured data sheets. Finally, all data compiled and statistical analysis was carried out by using IBM SPSS Statistics 22.0 (IBM Inc, Chicago, Illinois, USA). Result: Among 100 patients, 35\% were in sepsis group and $65 \%$ were in severe sepsis group. Fever was present in $97.1 \%$ cases, Heart rate $>90$ beats/min in $82.9 \%$, Tachypnea in $37.1 \%$, edema $5.7 \%$, Hyperglycemia in $25.7 \%$, Arterial hypoxemia in $22.9 \%$, Leukocytosis in $88.65 \%$ and Plasma C-reactive protein was $94.3 \%$.Sepsis induced arterial hypotension was $40 \%$, Hyperlactataemia was $44.6 \%$, Acute oliguria was $18.5 \%$, Acute lung injury with Pao2/Fio $2<200$ in the presence of pneumonia as infection source was $16.9 \%$, Creatinine $>2.0 \mathrm{mg} / \mathrm{dL}$ was $23.1 \%$, Serum bilirubin $>2 \mathrm{mg} / \mathrm{dL}$ was in $7.7 \%$, Thrombocytopenia was $38.5 \%$ and Coagulopathy was $21.5 \%$. Correlation of GCS score at seventh day with initial AMT score appeared to be particularly strong $(\mathrm{Rs}=0.663, \mathrm{P}<0.001)$. Blood Culture was positive in $8.2 \%$ only. Whereas Throat Swab culture is positive in $83.3 \%$ cases. Systemic hypotension $(\mathrm{P}=0.004)$, Hyperlactataemia $(\mathrm{P}=<0.001)$, Thrombocytopenia $(\mathrm{P}=0.020)$, Coagulation abnormalities $(\mathrm{P}=<0.001)$ differed significantly between survivor and non-survivor group. The female mortality was more $(27.27 \%)$ in severe sepsis group. Conclusion: This study will help the caregiver doctor to think in a systematic way for avoiding diagnostic delay and also highlights comparative values of different clinical and laboratory parameters. Statistical models can be developed based on similar clinical and laboratory variables that may help to develop criteria to predict different outcomes.

Keywords: sepsis, severe sepsis. Clinical and laboratory findings, hospital outcome.

Copyright $(\mathcal{C} 2020$ The Author(s): This is an open-access article distributed under the terms of the Creative Commons Attribution 4.0 International License (CC BY-NC 4.0) which permits unrestricted use, distribution, and reproduction in any medium for non-commercial use provided the original author and source are credited.

\section{INTRODUCTION}

Sepsis is defined as probable or documented infection with systemic manifestations of infection.
Severe sepsis is defined as sepsis plus sepsis-induced organ dysfunction or tissue hypo perfusion [1]. The clinical manifestations of sepsis are highly variable, depending on the initial site of infection, the causative 
organism, the pattern of acute organ dysfunction, the underlying health status of the patient, and the interval before initiation of treatment [2]. Respiratory compromise is classically manifested as the acute respiratory distress syndrome (ARDS), which is defined as hypoxemia with bilateral infiltrates of no cardiac origin [3]. Cardiovascular compromise is manifested primarily as hypotension or an elevated serum lactate level [1]. Acute kidney injury is manifested as decreasing urine output and an increasing serum creatinine level and frequently requires treatment with renal-replacement therapy, The laboratory parameters of patients with sepsis depend on initial conditions, co morbidity and acute organ dysfunction [4-6]. Prolonged Activated Partial Thromboplastin Time (APTT) and Prtothombin Time (PT) in patients with sepsis are associated with more severe forms of the disease; APTT is prolonged in no survivors, while platelet count and fibrinogen levels were higher in survivors [7]. Initial serum lactate is associated with mortality independent of clinically apparent organ dysfunction and shock in patients admitted to the inpatient ward or ICU with severe sepsis. Both intermediate and high serum lactate levels are independently associated with mortality [8]. Comorbidities that act as a risk factor and aggravating factor of sepsis were found among $88.1 \%$ of the subjects, comprising of diabetes mellitus, cardiovascular disease, cerebrovascular disease, and renal disease, malignancy, or HIV infection [9]. Recent study involving 14,000 ICU patients in 75 countries; gram-negative bacteria were isolated in $62 \%$ of patients with severe sepsis who had positive cultures, grampositive bacteria in 47\%, and fungi in 19\% [1]. Hospital mortality in ICU patients of Bangladesh suffering from severe sepsis was $49 \cdot 2 \%$ [11]. Hospital mortality was $44.5 \%$ (572/1285) in Asia [12].

Sepsis has considerably variable presentation, laboratory parameters and etiology in different regions. It demands early recognition, critical care and appropriate triage. This study will enable the physicians' for-early detection, initiation of treatment, appropriate referral for critical care support. There is no national guideline or consensus on diagnosis and management of sepsis in Bangladesh. So this study will serve as a basis of development of Bangladeshi population-based profile for sepsis.

\section{OBJECTIVES}

a) General objectives

To observe the clinical and laboratory profile of patients with sepsis

b) Specific objectives

To observe mortality and comorbidites of patients with sepsis

\section{Materials ANd Methods}

It was hospital- based cross- sectional, analytical observational study. This study was carried out in the Department of Medicine, Dhaka Medical College Hospital (DMCH). The Patients admitted in department of Medicine were the study population. Sepsis patients admitted in intensive care unit (ICU) of DMCH referred from the department of Medicine were included in the study. The study was carried out during the period from January 2015 to December 2015. The sampling method was non-random, and purposive. The patients who fulfilled the criteria of sepsis or sever sepsis and age more than 14 Years were enrolled in the study. Sepsis is defined as the presence (probable or documented) of infection together with systemic manifestations of infection. Infection, documented or suspected and some of the following: General variables; Fever $\left(>38.3^{\circ} \mathrm{C}\right.$ ) Hypothermia (core temperature < $36^{\circ} \mathrm{C}$ ) Heart rate $>90 / \mathrm{min}$ or more than two SD above the normal value for age, Tachypnea, Altered mental status, Significant oedema or positive fluid balance (> $20 \mathrm{~mL} / \mathrm{kg}$ over $24 \mathrm{hr}$.), Hyperglycaemia (plasma glucose $>140 \mathrm{mg} / \mathrm{dL}$ or $7.7 \mathrm{mmol} / \mathrm{L}$ ) in the absence of diabetes. - Inflammatory variables; Leukocytosis (WBC count $>12,000 / \mu \mathrm{L}$ ), Leukopenia (WBC count $<4000 /$ $\mu \mathrm{L})$, Normal WBC count with greater than $10 \%$ immature forms, Plasma C-reactive protein more than two SD above the normal value, Plasma procalcitonin more than two SD above the normal value. Hemodynamic variables; Arterial hypotension (SBP < $90 \mathrm{~mm} \mathrm{Hg}$, MAP < $70 \mathrm{~mm} \mathrm{Hg}$, or an SBP decrease > $40 \mathrm{~mm} \mathrm{Hg}$ in adults or less than two SD below normal for age). Organ dysfunction variables; Arterial hypoxemia (Pao2/Fio2 < 300), Acute oliguria (urine output $<0.5 \mathrm{~mL} / \mathrm{kg} / \mathrm{hr}$ for at least $2 \mathrm{hrs}$ despite adequate fluid resuscitation), Creatinine increase $>0.5 \mathrm{mg} / \mathrm{dL}$ or $44.2 \mu \mathrm{mol} / \mathrm{L}$, Coagulation abnormalities (INR > 1.5 or APTT > 60 s), Ileus (absent bowel sounds), Thrombocytopenia (platelet count $<100,000 / \mu \mathrm{L}$ ), Hyperbilirubinemia (plasma total bilirubin $>4 \mathrm{mg} / \mathrm{dL}$ or $70 \mu \mathrm{mol} / \mathrm{L})$. Tissue perfusion variables; Hyperlactatemia (lactate, $>1 \mathrm{mmol} / \mathrm{liter}$.) Decreased capillary refill or mottling. Severe sepsis: ${ }^{1}$ Severe sepsis is defined as sepsis plus sepsis-induced organ dysfunction or tissue hypo perfusion (any of the following thought to be due to the infection).(Sepsisinduced hypotension, Lactate above upper limits laboratory normal,, Urine output $<0.5 \mathrm{~mL} / \mathrm{kg} / \mathrm{hr}$ for more than 2 hrs despite adequate fluid resuscitation., Acute lung injury with Pao2/Fio $2<250$ in the absence of pneumonia as infection source., Acute lung injury with Pao2/Fio2 < 200 in the presence of pneumonia as infection source,Creatinine $>2.0 \mathrm{mg} / \mathrm{dL} \quad(176.8$ $\mu \mathrm{mol} / \mathrm{L})$, ,Bilirubin $>2 \mathrm{mg} / \mathrm{dL}(34.2 \mu \mathrm{mol} / \mathrm{L})$, Platelet count $<100,000 \mu \mathrm{L}$, Coagulopathy (international normalized ratio > 1.5). Exclusion criteria: Age: <14years, Decompensated liver cirrhosis, Nephrotic syndrome, Hematological malignancy, Pregnancy, Acute coronary syndrome, the patients who did not give consent. 
Data was collected in a pre-designed proforma. Patients' information was obtained using information sheet which includes questionnaire, clinical findings and investigation findings. Severity of sepsis was categorized based on clinical and laboratory parameters recorded during the study. Attempt was made to find association of different outcome variables (i.e. Glasgow Coma Score, mortality, need of ICU support and severity of sepsis) with different clinical and laboratory parameters. For such purpose different statistical tests was utilized considering various measurement levels of variables. Finally, all data compiled together and statistical analyses was carried out by using IBM SPSS Statistics 22.0 (IBM Inc, Chicago, Illinois, USA) \& MS-Excel 2016. Significance of relationship between important categorical variables was demonstrated using cross-tables with Pearson's Chi-squared test Statistical significance was deemed while $\mathrm{P}<0.05$ at $95 \%$ confidence interval.

\section{RESULTS}

During the study period, among 100 patients, 35 patients were in sepsis group where 65 patients were in severe sepsis group according to the clinical practice guideline. Surviving Sepsis Campaign (SSC): International Guidelines for Management of Severe Sepsis and Septic Shock: 2012). These two groups were observed separately in subsequent observation. Distribution of male and female patients in different age groups. It was observed that male was [66 (66\%)] and female was [34 (34\%)]. The male: female ratio was approximately $1.9: 1$. Among the study population, more male [24 $(36.4 \%)$ ] belonged to $14-40$ years age group while more female [10 (29.4\%)] were in 51-60 years age group[Table-I]. Graphical presentation of percentage of sepsis $35 \%$ and severe sepsis $65 \%$. Distribution of cases classified as sepsis who fulfilled different clinical and laboratory parameters to qualify the diagnostic criteria of sepsis as proposed by Surviving Sepsis Campaign excluding severe sepsis cases. It was observed that Fever was present in [34 $(97.1 \%)]$ cases, Heart rate $>90$ beats $/ \mathrm{min}$ in $[29$ $(82.9 \%)]$, Tachypnea in [13 $(37.1 \%)]$, edema [2(5.7\%)] Hyperglycemia in [9 (25.7\%)], Arterial hypoxemia in [8(22.9\%)], Leukocytosis in [31 (88.65\%)] and Plasma C-reactive protein was [33 (94.3\%)], Decreased capillary refill had [1(2.9\%)].WBC count was normal in [4(11.1\%)]. There was 7\% patient had Leukocytopenia but that was merged with severe sepsis[Table-II]. We found that Sepsis induced arterial hypotension was [26 (40\%)], Hyperlactataemia was [ 29 (44.6\%)], Acute oliguria was $[12(18.5 \%)]$, Acute lung injury with Pao2/Fio2 $<200$ in the presence of pneumonia as infection source was [11 (16.9\%)], Creatinine > 2.0 $\mathrm{mg} / \mathrm{dL}$ was $[15(23.1 \%)]$, Serum bilirubin $>2 \mathrm{mg} / \mathrm{dL}$ was [5 (7.7\%)], Thrombocytopenia was [25 (38.5\%)] and Coagulopathy was [14 (21.5\%)][Table-III]. Correlation of baseline clinical and laboratory parameters with Glasgow Coma Score recorded at seventh day of admission. Correlation of GCS score at seventh day with initial AMT score appeared to be particularly strong $(\mathrm{Rs}=0.663, \mathrm{P}<0.001$. Statistically significant $(\mathrm{P}<0.05)$ positive correlations were noted also systolic blood pressure, mean arterial pressure, respiratory rate, bowel sound and platelet count whereas negative correlations were found for acute oliguria, peripheral oedema, capillary refill time, fluid balance, random blood glucose, International Normalized Ratio, activated partial thromboplastin time, serum creatinine and serum lactate[Table-IV]. Graphical presentation of mortality among different sepsis category distributed according to different age groups and sex. Upper left quadrant shows distribution of mortality among different age groups in male sepsis patients. Upper right quadrant shows distribution of mortality among different age groups in male severe sepsis patients. Lower left quadrant shows distribution of mortality among different age groups in female sepsis patients. Lower right quadrant shows distribution of mortality among different age groups in female severe sepsis patients. It was observed that 7 days mortality was [14 $(14 \%)]$. It was found that mortality was [13 (20\%)] in severe sepsis group and [1 $(2.8 \%)]$ in sepsis group. [1 $(4.35 \%)$ ] male mortality, with no female mortality in sepsis group was observed. We also found that the male mortality was [7 (16.2\%)] and the female mortality was [6 $(27.27 \%)$ ] in severe sepsis group[Figure-II]. Distribution of cases with different comorbidities in sepsis and sever sepsis and different sepsis category. This figure shows CKD followed by stroke, Hypertension, Diabetes mellitus were more common comorbid condition in severe sepsis group. Whereas COPD followed by IHD and Diabetes Mellitus were more common comorbid condition in sepsis group. Current data did not show any statistically significant distribution of comorbidities between the sepsis categories[Figure-III].

Table-I: Distribution of male and female patients in different age groups $(\mathrm{N}=100)$

\begin{tabular}{|c|c|c|c|c|c|}
\hline \multicolumn{2}{|c|}{$\begin{array}{c}\text { Demographic } \\
\text { character }\end{array}$} & \multicolumn{2}{c|}{ Male } & \multicolumn{2}{c|}{ Female } \\
\cline { 2 - 6 } & n & \% & n & \% \\
\hline \multirow{3}{*}{$\begin{array}{c}\text { Age } \\
\text { group }\end{array}$} & $14-40$ & 24 & 36.36 & 8 & 23.53 \\
\cline { 2 - 6 } & $41-50$ & 12 & 18.18 & 8 & 23.53 \\
\cline { 2 - 6 } & $51-60$ & 14 & 21.21 & 10 & 29.41 \\
\cline { 2 - 6 } & $61-70$ & 12 & 18.18 & 5 & 14.71 \\
\cline { 2 - 6 } & $71-80$ & 4 & 6.06 & 2 & 5.88 \\
\cline { 2 - 6 } & $>80$ & 0 & 0 & 1 & 2.94 \\
\hline
\end{tabular}




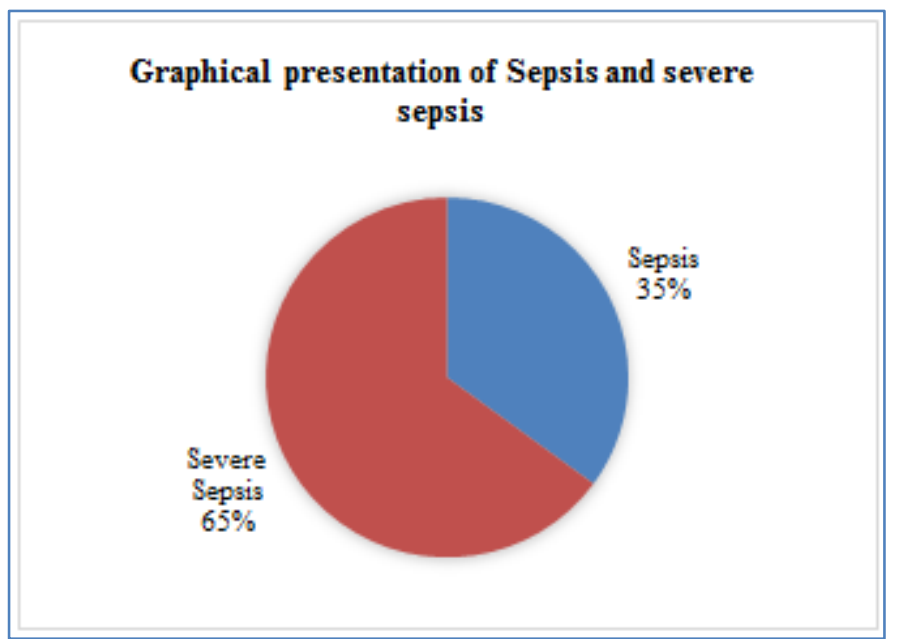

Fig-I: Graphical Presentation of Sepsis and Severe Sepsis (N=100)

Table-II: Distribution of cases fulfilling different clinical and laboratory parameters to qualify the diagnostic criteria of sepsis as proposed by Surviving Sepsis Campaign $(n=35)$

\begin{tabular}{|c|c|c|}
\hline \multirow[b]{2}{*}{ Criteria of Sepsis $(n=35)$} & \multicolumn{2}{|c|}{ Present } \\
\hline & $\mathbf{n}$ & $\%$ \\
\hline \multicolumn{3}{|l|}{ General variables } \\
\hline Fever & 34 & $97.10 \%$ \\
\hline Hypothermia (core temperature $<36^{\circ} \mathrm{C}$ ) & 1 & $2.90 \%$ \\
\hline Heart rate $>90$ beats/min or more than two SD above the normal value for age & 29 & $82.90 \%$ \\
\hline Tachypnea (respiratory rate $>20$ breaths/min) & 13 & $37.10 \%$ \\
\hline Altered mental status (Abbreviated Mental Test score < 9) & 16 & $45.70 \%$ \\
\hline Significant edema or positive fluid balance $(>20 \mathrm{~mL} / \mathrm{kg}$ over $24 \mathrm{hr})$ & 2 & $5.70 \%$ \\
\hline Hyperglycemia (plasma glucose $>140 \mathrm{mg} / \mathrm{dL}$ or $7.7 \mathrm{mmol} / \mathrm{L}$ ) in the absence of diabetes & 9 & $25.70 \%$ \\
\hline \multicolumn{3}{|l|}{ Inflammatory variables } \\
\hline Leukocytosis (WBC count > 12000/microliter) & 31 & $88.60 \%$ \\
\hline Leukocytopenia (WBC count < 4000/microliter) & 0 & $0.00 \%$ \\
\hline Normal WBC count with greater than $10 \%$ immature forms & 0 & $0.00 \%$ \\
\hline Plasma C-reactive protein more than two SD above the normal value & 33 & $94.30 \%$ \\
\hline \multicolumn{3}{|l|}{ Hemodynamic variables } \\
\hline $\begin{array}{l}\text { Sepsis induced arterial hypotension (SBP }<90 \mathrm{~mm} \mathrm{Hg}, \text { MAP }<70 \mathrm{~mm} \mathrm{Hg} \text {, or an SBP } \\
\text { decrease }>40 \mathrm{~mm} \mathrm{Hg} \text { in adults or less than two SD below normal for age) }\end{array}$ & 0 & $0.00 \%$ \\
\hline \multicolumn{3}{|l|}{ Organ dysfunction variables } \\
\hline Arterial hypoxemia $(\mathrm{PaO} 2 / \mathrm{FiO} 2<300)$ & 8 & $22.90 \%$ \\
\hline $\begin{array}{c}\text { Acute oliguria (urine output }<0.5 \mathrm{~mL} / \mathrm{kg} / \mathrm{hr} \text { for at least } 2 \mathrm{hrs} \text { despite adequate fluid } \\
\text { resuscitation) }\end{array}$ & 0 & $0.00 \%$ \\
\hline Creatinine increase $>0.5 \mathrm{mg} / \mathrm{dL}$ or $44.2 \mathrm{micromol} / \mathrm{L}$ & 6 & $17.10 \%$ \\
\hline Coagulation abnormalities (INR > 1.5 or aPTT $>60 \mathrm{~s}$ ) & 0 & $0.00 \%$ \\
\hline Ileus (absent bowel sounds) & 0 & $0.00 \%$ \\
\hline Thrombocytopenia (platelet count $<100,000 /$ microliter) & 0 & $0.00 \%$ \\
\hline Hyperbilirubinemia (plasma total bilirubin $>4 \mathrm{mg} / \mathrm{dL}$ or $70 \mathrm{micromol} / \mathrm{L}$ ) & 0 & $0.00 \%$ \\
\hline \multicolumn{3}{|l|}{ Tissue perfusion variables } \\
\hline Hyperlactataemia (serum lactate $>1 \mathrm{mmol} / \mathrm{L}$ ) & 0 & $0.00 \%$ \\
\hline Decreased capillary refill or mottling & 1 & $2.90 \%$ \\
\hline
\end{tabular}


Table-III: Distribution of cases fulfilling different clinical and laboratory parameters to qualify the diagnostic criteria of severe sepsis as proposed by Surviving Sepsis Campaign $(n=65)$

\begin{tabular}{|c|c|c|}
\hline \multirow[t]{2}{*}{ Criteria of Severe sepsis $(n=65)$} & \multicolumn{2}{|c|}{ Present } \\
\hline & $\mathbf{n}$ & $\%$ \\
\hline $\begin{array}{l}\text { Sepsis induced arterial hypotension }(\mathrm{SBP}<90 \mathrm{~mm} \mathrm{Hg} \text {, MAP }< \\
70 \mathrm{~mm} \mathrm{Hg} \text {, or an SBP decrease }>40 \mathrm{~mm} \mathrm{Hg} \text { in adults or less } \\
\text { than two SD below normal for age) }\end{array}$ & 26 & $40.00 \%$ \\
\hline Hyperlactataemia (serum lactate $>1 \mathrm{mmol} / \mathrm{L}$ ) & 29 & $44.60 \%$ \\
\hline $\begin{array}{l}\text { Acute oliguria (urine output }<0.5 \mathrm{~mL} / \mathrm{kg} / \mathrm{hr} \text { for at least } 2 \mathrm{hrs} \\
\text { despite adequate fluid resuscitation) }\end{array}$ & 12 & $18.50 \%$ \\
\hline $\begin{array}{l}\text { Acute lung injury with } \mathrm{Pao} 2 / \mathrm{Fio} 2<250 \text { in the absence of } \\
\text { pneumonia as infection source }\end{array}$ & 0 & $0.00 \%$ \\
\hline $\begin{array}{l}\text { Acute lung injury with } \mathrm{Pao} 2 / \mathrm{Fio} 2<200 \text { in the presence of } \\
\text { pneumonia as infection source }\end{array}$ & 11 & $16.90 \%$ \\
\hline Creatinine $>2.0 \mathrm{mg} / \mathrm{dL}(176.8 \mathrm{micromol} / \mathrm{L})$ & 15 & $23.10 \%$ \\
\hline Serum bilirubin $>2 \mathrm{mg} / \mathrm{dL}(34.2 \mathrm{micromol} / \mathrm{L})$ & 5 & $7.70 \%$ \\
\hline Thrombocytopenia (platelet count $<100,000$ /microliter) & 25 & $38.50 \%$ \\
\hline Coagulopathy (international normalized ratio > 1.5) & 14 & $21.50 \%$ \\
\hline
\end{tabular}

Table-VI: Correlation of baseline clinical and laboratory parameters with Glasgow Coma Score recorded at seventh day of admission ( $N=100)$

\begin{tabular}{|c|c|c|}
\hline Variables & $\begin{array}{c}\text { Spearman's Rank } \\
\text { Correlation } \\
\text { Coefficient (rs) }\end{array}$ & $\begin{array}{c}\text { Level of } \\
\text { significance } \\
\left.(\text { P-value })^{*}\right)\end{array}$ \\
\hline Age & -0.12 & 0.233 \\
\hline Sex & -0.153 & 0.128 \\
\hline Fever & 0.128 & 0.205 \\
\hline Duration of fever (in days) & 0.106 & 0.292 \\
\hline ATM Score & 0.663 & $<0.001$ \\
\hline Dyspnoea & 0.152 & 0.13 \\
\hline Acute oliguria & -0.233 & 0.019 \\
\hline Jaundice & -0.041 & 0.019 \\
\hline Pulse & 0.11 & 0.687 \\
\hline SBP & 0.255 & 0.277 \\
\hline MAP & 0.31 & 0.01 \\
\hline Temperature & 0.196 & 0.002 \\
\hline Respiratory rate & 0.355 & 0.05 \\
\hline Peripheral oedema & -0.342 & $<0.001$ \\
\hline Bowel sound & 0.248 & 0.013 \\
\hline Capillary refill time & -0.249 & 0.012 \\
\hline Fluid balance & -0.416 & $<0.001$ \\
\hline Random blood glucose & -0.339 & 0.001 \\
\hline TCWBC & 0.043 & 0.673 \\
\hline Platelet count & 0.211 & 0.035 \\
\hline C-reactive protein & 0.046 & 0.648 \\
\hline INR & -0.293 & 0.003 \\
\hline APTT & -0.37 & $<0.001$ \\
\hline Serum creatinine & -0.238 & 0.017 \\
\hline Serum bilirubin & -0.041 & 0.689 \\
\hline Serum lactate & -0.43 & $<0.001$ \\
\hline Blood cultures positivity & 0.074 & 0.463 \\
\hline
\end{tabular}




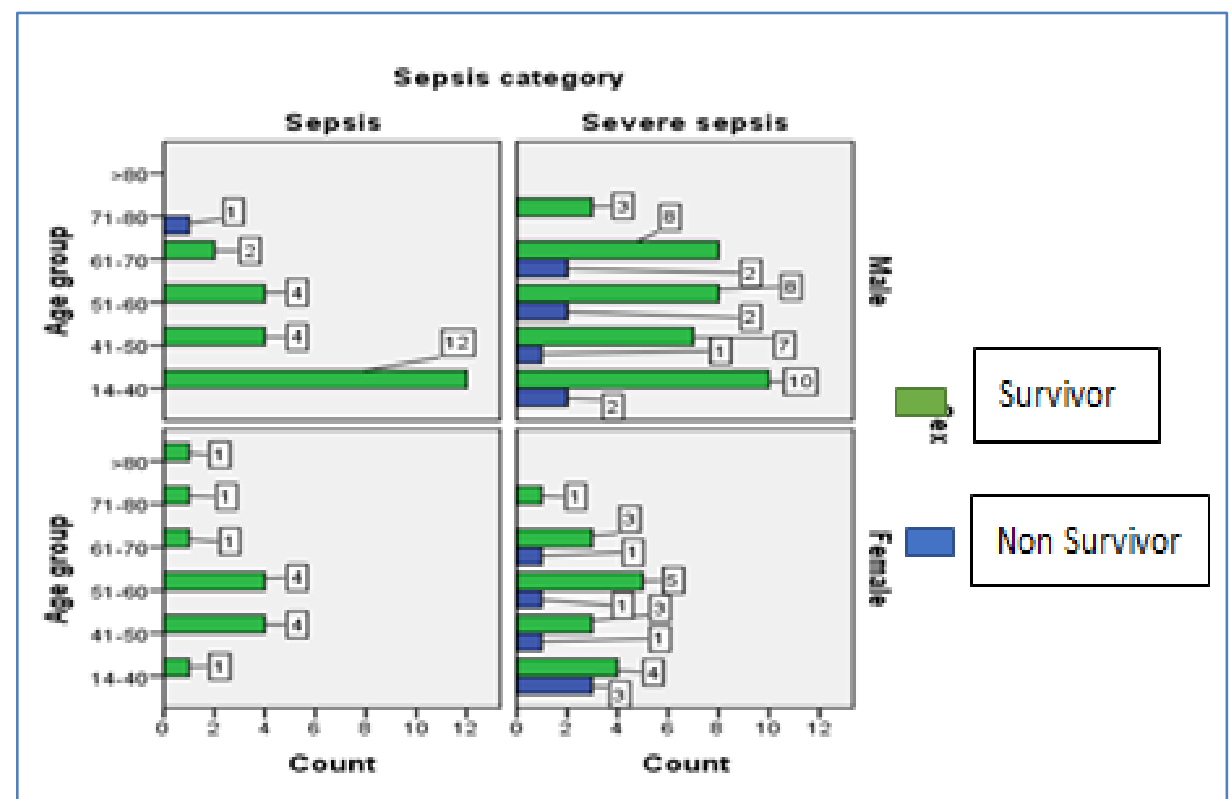

Fig-II: Graphical presentation of mortality among sepsis and severe sepsis according to different age groups and sex

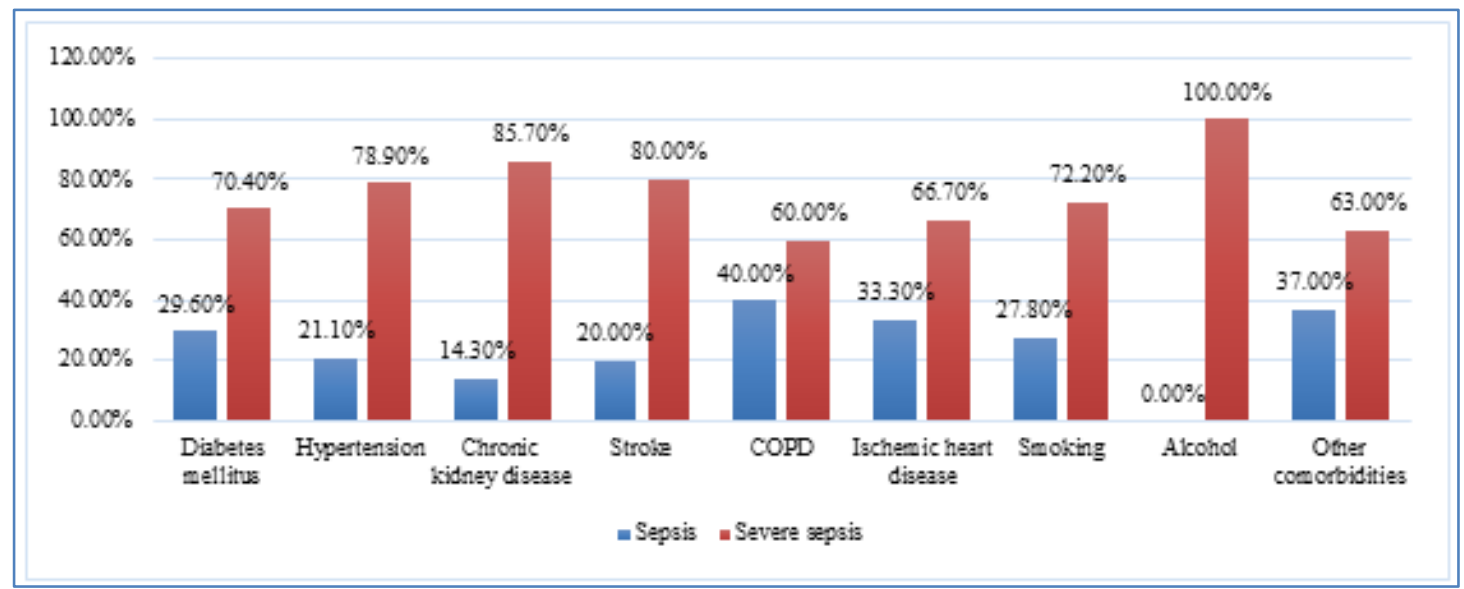

Fig-III: Distribution of cases with different comorbidities in sepsis and severe sepsis

\section{DISCUSSION}

In present study male were $66(66 \%)$ and female were $34(34 \%)$. The male: female ratio was approximately 1.9:1. This indicates that sex distribution revealed male predominance among the study population. More male $12(70 \%)$ belonged to $61-70$ years age group while more female $24(41 \%)$ were in 51-60 years age group. Overall, $24(75 \%)$ of study population were below 40 years of age. Thirty six percent $(36 \%)$ patient were smoker. Similarly, an Indian study by Prashanth [10] showed among 100 sepsis patients studied, 60 were male $(60 \%)$ and 40 were female $(40 \%)$. The patient's age ranged from 18 to 88 years (mean 41.85). An Indonesian study showed out of fourty two 11(28.6) were more than 60 years and male were $52.4 \%$, female was $47.65 \%$. Which support our study result [9]. Phua J [11]. Observed mean age 59.2 years, male was $61.7 \%$. Another study done by Faruq [12] in Bangladesh obtained that Age (years) $52.3 \pm$ 19.7 were in Survivors and 55.6 $\pm 15 \cdot 6$ Non-survivors, male were $44 \%$ and female were $55 \%$ which differ with the current study. This difference result may be due to they included surgical, gynecological and medical cases. There sample were only severe sepsis. In a study from New Delhi by Nasa ${ }^{13}$ showed 132 of 387 (34\%) patients were sepsis that was similar to our study. Widodo [9] showed, 42 subjects who participated in the study, eleven subjects fulfilled the criteria for sepsis (26.2\%), 20 subjects for severe sepsis (47.6\%), and 11 subjects for septic shock $(26.2 \%)$. B. Khwannimit and R. Bhurayanontachai [14] showed that the incidence of severe sepsis and septic shock increased significantly from 16.6 to 21.6/100 ICU admissions in Thailand hospital. Severe sepsis and septic shock were identified in $87(22.3 \%)$ and $303(77.7 \%)$ patients respectively. Martin [15] founded that the number of sepsis cases increased from 164,072 in 1979 to 659,935 in 2000. This was an increase of 13.7 percent per year. Our study as well as other study done by many investigators show incidence of severe sepsis increasing day by day with increased mortality, probably due to late presentation, unable to early recognition and delay of management. With advancement of medical management this 
scenario is unexpected. An emergency mass awareness programmed is important to combat the situation.

Mean temperature, respiratory rate, heart rate did not differ among the non-survivors, survivors, sepsis and severe-sepsis respectively. Heart rate more than 90 beat per minute $(82.9 \%)$ and respiratory rate $>20$ breath per minute $(37.1 \%)$ were found in our study population, Widodo [9] in Indonesia recorded heart rate $100 \%$ and respiratory rate $(95.2 \%)$, the result differed with our result because most of our study population were in ventilator support in ICU. There is no similar study on single factor effect. Fever $(97.1 \%)$ was important and common presenting complaint which duration did not varied among sepsis, severe sepsis, survivors and non-survivors. Cases with sepsis induced arterial hypotension, acute oliguria, coagulation abnormalities, thrombocytopenia, hyperbilirubinemia, and hyperlactataemia were not found in sepsis group as these variables were overlapped in the criteria of sepsis and severe sepsis. Hyperglycemia in absence of diabetes was found $25.7 \%$ in this study. But there is no other study result is available about this factor. In sepsis, leukocytosis (WBC count> 12,000/microliter) was $88.6 \%$ in our series, $78 \%$ in Widodo [9] study in Indonesia. CRP was $94.3 \%$ in our study. Yi-Ling Chan [20], recorded $67.1 \%$ of infected patients in their study. This disparity due to may be different cut of value. Edema or positive fluid balance (>20 ml/kg/over 24 hrs.) was $5.7 \%$, which was $25.04 \pm 22.95$ in nonsurvivor. Positive fluid balance $(\mathrm{P}<0.001)$ was significantly associated with mortality and influence the GCS in our study. Acheampong and Jean-Luis Vincent [21] also concluded that persistent of positive daily fluid balance over time was quite strongly associated with mortality in septic patient.

We found that Sepsis induced arterial hypotension was $26(40 \%)$, hyperlactataemia was 29 (44.6\%), acute oliguria was $12(18.5 \%)$, acute lung injury with Pao2/Fio2 $<200$ in the presence of pneumonia as infection source was 11 (16.9\%), creatinine $>2.0 \mathrm{mg} / \mathrm{dL}$ was $15(23.1 \%)$, serum bilirubin $>2 \mathrm{mg} / \mathrm{dL}$ was $5(7.7 \%)$, thrombocytopenia was 25 (38.5\%) and coagulopathy was $14(21.5 \%)$. According to Mikkelsen [8] it was 351(42.3\%), 382(46\%), 52(6.3\%), 94(11.3\%), 223(26.9\%), 99(11.9\%), 127 $(15.3 \%), 91(11 \%)$ respectively all result is similar with this study, except acute oliguria and thrombocytopenia.

Fluid balance, Urine output, AMT score, Initial GCS score, $\mathrm{pH}$, Arterial blood bicarbonate, Fraction of oxygen in the inspired air (FIO2) (\%), differed significantly among sepsis, severe sepsis, survivors and non-survivors. Correlation of GCS score at seventh day with initial AMT score appeared to be particularly strong $(\mathrm{Rs}=0.663, \mathrm{P}<0.001$. Statistically significant $(\mathrm{P}<0.05)$ positive correlations were noted also systolic blood pressure, mean arterial pressure, respiratory rate, bowel sound and platelet count whereas negative correlations were found for acute oliguria, peripheral oedema, capillary refill time, fluid balance, random blood glucose, International Normalised Ratio, activated partial thromboplastin time, serum creatinine and serum lactate. In this series blood culture was positive in $7(8.2 \%)$ only, whereas throat swab culture in $5(83.3 \%)$ tracheal aspirate culture in $16(72.7 \%$.) were positive. Pseudomonas spp was commonest organism identified in throat swap culture. Most of the organism isolated in Tracheal aspirate were Pseudomonas spp. 5 (22.7\%), E. coli [4 (18.2\%)], Gram-Positive cocci 3 (13.6\%), Acinetobacter 2 (9.1\%) and Klebsiella spp. 2 (9.1\%). Fungal isolate (Candida spp.) were positive in blood $1(1.2 \%)$ and urine 1 $(1.9 \%)$. The similar result was found in study done by Widodo [9] in Indonesia, Zhou [15] in China, Prashanth [10] in India, B. Khwannimit and R. Bhurayanontachai [14] in Thailand, Zanon [16] in Brazil. In our study Fungimia was $1.2 \%$, Zanon showed [16] $1.3 \%$ in their study.

In this series most of the patient had comorbidities. Of the comorbidity DM, HTN, CKD, CVD, COPD, IHD present in 27(27\%), 19(19\%), 7(7\%), 15(15\%), 5(5\%), 6(6\%) respectively. Oppert M [17] differs with this result DM in 100 (52.2\%), CKD in $37(20 \%)$, CVD in $50(29.7 \%)$, hypertension in $170(85 \%)$, COPD in 50(14.6\%) and Widodo [9] showed similarity with DM in $14(33.3 \%)$ and CVD in 5 $(11.9 \%)$ but differ with other co-morbidities. This dissimilarity may be due to, in our study we enrolled medical conditions only and excluded Hematological malignancy, CLD, Nephrotic syndrome, acute coronary syndrome, pregnancy and trauma and surgical patients. But they enrolled medical, surgical and gynecological patients in their study. It was observed that 7 days mortality was $14(14 \%)$. It was found that mortality was $13(20 \%)$ in severe sepsis group and $1(2.8 \%)]$ in sepsis group. We also found that the male mortality was 7 $(16.2 \%)$ and the female mortality was $6(27.27 \%)$ in severe sepsis group. Blanco $\mathrm{J}$ [18] reported that the mortality in $1^{\text {st }} 48 \mathrm{~h}$ was $14.8 \%$ which is consistent with our result. Zanon [26] showed $22.2 \%$ mortality in severe sepsis group which is consistent with our study also but $10.1 \%$ mortality in sepsis group which differ from us that was $2.8 \%$. Another study demonstrated a mortality rate of $11(28 \%)$ within first 48 hours. The highest mortality rate was found in the age group $\geq 65$ years. The study demonstrated a higher incidence of sepsis in men compared to women, Pradipta [19] which differs with our study. In terms of mortality rate, Sudjito [22] show a higher mortality rate in women than in men which support our study result. Faruq [12] observed Most (78.9\%) of the patients died within 28 days of admission.

\section{Limitations of the Study}

The study population was selected from Medicine department and intensive care unit of a single tertiary level centre in Dhaka city. So that the results of 
the study may not reflect the exact picture of the country. The present study was conducted within a very short period of time. Small sample size was also a limitation of the present study. Another limitation was that patients were followed up only once at the end of first week after enrolment in the study. It was too small compared to severe sepsis patient population of Bangladesh, so an accurate epidemiology, clinical features, laboratory parameter and hospital outcome of sepsis patient was difficult to obtain from this study.

\section{CONCLUSION \& RECOMMENDATION}

From this study, it is concluded that severe sepsis is very common at a tertiary level hospital in Dhaka. Sever sepsis kills many of our patient silently. Elderly patients are suffering more in sepsis in with many comorbid condition. Clinical symptom, sign and laboratory profile are varying with individual patients. Mortality is higher among female sepsis patients. It is prism that the significant reason for the higher mortality may be due to late presentation in the health care centre, to delay in diagnosis and subsequent delay in initiation of treatment. Initial GCS and fever duration can help to predict need for ICU support. Serum Lactate, Platelet count, APTT, INR and Arterial blood bicarbonate are important investigations for assessing severity of sepsis. Fluid balance, urine output, AMT score, initial GCS score, $\mathrm{pH}$, arterial blood bicarbonate, FIO2 are strongly correlated with the severity of sepsis and mortality and therefore, should be extensively monitored. Female patients with severe sepsis need more intensive care due to presence of higher mortality. This study can serve as a pilot to a much larger research involving multiple centers that can provide a nationwide picture, validate regression models proposed in this study for future use.

\section{REFERENCES}

1. Dellinger RP, Levy MM, Rhodes A, Annane D, Gerlach H, Opal SM, Sevransky JE, Sprung CL, Douglas IS, Jaeschke R, Osborn TM. Surviving Sepsis Campaign: international guidelines for management of severe sepsis and septic shock, 2012. Intensive care medicine. 2013 Feb 1;39(2):165-228.

2. Levy MM, Fink MP, Marshall JC, Abraham E, Angus D, Cook D, Cohen J, Opal SM, Vincent JL, Ramsay G. $2001 \quad$ sccm/esicm/accp/ats/sis international sepsis definitions conference. Intensive care medicine. 2003 Apr 1;29(4):530-8.

3. Force AD, Ranieri VM, Rubenfeld GD, Thompson BT, Ferguson ND, Caldwell E. Acute respiratory distress syndrome. Jama. 2012 Jun 20;307(23):2526-33.

4. Giamarellos-Bourboulis EJ, Giannopoulou P, Grecka P, Voros D, Mandragos K, Giamarellou H. Should procalcitonin be introduced in the diagnostic criteria for the systemic inflammatory response syndrome and sepsis?. Journal of critical care. 2004 Sep 1;19(3):152-7.
5. Uzzan B, Cohen R, Nicolas P, Cucherat M, Perret GY. Procalcitonin as a diagnostic test for sepsis in critically ill adults and after surgery or trauma: a systematic review and meta-analysis. Critical care medicine. 2006 Jul 1;34(7):1996-2003.

6. Tang BM, McLean AS, Dawes IW, Huang SJ, Lin RC. The use of gene-expression profiling to identify candidate genes in human sepsis. American journal of respiratory and critical care medicine. 2007 Oct 1;176(7):676-84.

7. Mihajlovic D, Lendak D, Mitic G, Cebovic T, Draskovic B, Novakov A, Brkic S. Prognostic value of hemostasis-related parameters for prediction of organ dysfunction and mortality in sepsis. Turkish Journal of Medical Sciences. 2015 Jan 27;45(1):93-8.

8. Mikkelsen, M. E., Miltiades, A. N., Gaieski, D. F., Goyal, M., Fuchs, B. D., Shah, C. V., \& Christie, J. D. (2009). Serum lactate is associated with mortality in severe sepsis independent of organ failure and shock. Critical care medicine, 37(5), 1670-1677.

9. Widodo D. The clinical, laboratory, and microbiological profile of patients with sepsis at the internal medicine inpatient unit of Dr. Cipto Mangunkusumo National General Hospital, Jakarta. Medical Journal of Indonesia. 2004 May $1 ; 13(2): 90-5$.

10. Prashanth H, Saldanha RD, Shenoy S, Baliga S. Predictors of mortality in adult sepsis. Int $\mathrm{J}$ Biol Med Res. 2011;2(4):856-61.

11. Phua J, Koh Y, Du B, Tang YQ, Divatia JV, Tan CC, Gomersall CD, Faruq MO, Shrestha BR, Binh NG, Arabi YM. Management of severe sepsis in patients admitted to Asian intensive care units: prospective cohort study. Bmj. 2011 Jun 13;342.

12. Faruq MO, Ahsan AA, Uddin MN, Khatun US, Mannan MA, Tamanna RJ, Fatema K, Ahmed F, Nooruzzaman AR, Maniruzzaman M, Rahman AS. Implementation of sepsis bundles in intensive care units of Bangladesh: A prospective observational study. Bangladesh Critical Care Journal. 2013 Mar 30;1(1):8-17.

13. Nasa P, Juneja D, Singh O, Dang R, Arora V. Severe sepsis and its impact on outcome in elderly and very elderly patients admitted in intensive care unit. Journal of intensive care medicine. 2012 May;27(3):179-83.

14. Khwannimit B, Bhurayanontachai R. The epidemiology of, and risk factors for, mortality from severe sepsis and septic shock in a tertiarycare university hospital setting. Epidemiology \& Infection. 2009 Sep;137(9):1333-41.

15. Martin GS, Mannino DM, Eaton S, Moss M. The epidemiology of sepsis in the United States from 1979 through 2000. New England Journal of Medicine. 2003 Apr 17;348(16):1546-54.

16. Zhou J, Qian C, Zhao M, Yu X, Kang Y, Ma X, Ai Y, Xu Y, Liu D, An Y, Wu D. Epidemiology and outcome of severe sepsis and septic shock in 
intensive care units in mainland China. PloS one. 2014 Sep 16;9(9):e107181.

17. e Mortalidade FP. Sepsis in the intensive care unit: etiologies, prognostic factors and mortality. Revista Brasileira de terapia intensiva. 2008 Apr;20(2).

18. Oppert M, Engel C, Brunkhorst FM, Bogatsch H, Reinhart K, Frei U, Eckardt KU, Loeffler M, John S, German Competence Network Sepsis (Sepnet). Acute renal failure in patients with severe sepsis and septic shock - a significant independent risk factor for mortality: results from the German Prevalence Study. Nephrology Dialysis Transplantation. 2008 Mar 1;23(3):904-9.

19. Blanco J, Muriel-Bombín A, Sagredo V, Taboada F, Gandía F, Tamayo L, Collado J, García-Labattut Á, Carriedo D, Valledor M, De Frutos M. Incidence, organ dysfunction and mortality in severe sepsis: a Spanish multicentre study. Critical care. 2008 Dec 1;12(6):R158.

20. Pradipta IS, Sandiana AT, Halimah E, Diantini A, Lestari K, Abdulah R. Microbial and resistance profile in isolate from adult sepsis patients: An observational study at an Indonesian private hospital during 2009-2012. age. 2009 Jan;2012.

21. Chan YL, Liao HC, Tsay PK, Chang SS, Chen JC, Liaw SJ. C-reactive protein as an indicator of bacterial infection of adult patients in the emergency department. Chang Gung medical journal. 2002 Jul 1;25(7):437-45.

22. Acheampong A, Vincent JL. A positive fluid balance is an independent prognostic factor in patients with sepsis. Critical care. 2015 Dec $1 ; 19(1): 251$.

23. UH Sudjito, AR Suharto - skp.unair.ac.id: http://repository.unair.ac.id/id/eprint/63245. 